\title{
A HYBRID APPROACH TO FAKE NEWS DETECTION ON SOCIAL MEDIA
}

\author{
E. M. Okoro ${ }^{1,}{ }^{*}$, B. A. Abara ${ }^{2}$, A. 0. Umagba ${ }^{3}$, A. A. Ajonye ${ }^{4}$ and Z. S. Isa ${ }^{5}$ \\ 1,2,3,45, NATIONAL Institute of Construction Technology, Uromi-Ugboha RoAd, Uromi, Edo State, NigERIA. \\ Email addresses:1 efeosasere@gmail.com, ${ }^{2}$ b.abara@nict.edu.ng, ${ }^{3}$ a.umagba@nict.edu.ng, \\ 4 a.ajonye@nict.edu.ng, ${ }^{5}$ z.isa@nict.edu.ng
}

\begin{abstract}
Fake news has grown tremendously in recent times and this growth has had a great impact on how we make a number of sensitive decisions daily including becomes our President. There have been a wide range of solutions developed to help humans distinguish between fake and real news however, the solutions rely on either a machinebased approach or a human-based approach to detection. Research in the fields of computer science, artificial intelligence and psychology research has shown the limitations in both approaches. Based on these research findings, this paper proposes a hybrid model for detecting fake news on social media using a combination of both the humanbased and machine-based detection approaches.
\end{abstract}

Keywords: Fake news detection; Human decision making; Machine decision making

\section{INTRODUCTION}

News is very important because it keeps the public updated on events and occurrences around them and beyond their immediate environment. Reports have shown that a majority of adults access their news using digital forms such as social media and traditional search engines [1] rather than using traditional media. However, an incident occurred in the 18th century that changed news reporting forever. This was the birth of fake news. However, its increasing level as it stands today would not have been possible without the introduction of the internet.

Internet and social media made it easier to spread deceptive news. Fake news has numerous impacts. There are claims it even influenced the American election.

The problems with fake news are:

(1) Reports shows that over a trillion posts are made on the internet per second mostly through social media platforms like Facebook and Twitter making traditional facts checking impossible. The reports in [2-4] emphasized this by adding that "traditional fact checking by expert journalist cannot keep up with enormous volume of information that is now generated online". Sometimes a social media user without any journalism reputation can in some cases get more views on their publication than one written by televised media houses like CNN or NTA and newspaper publishing companies like the New York Times, The Guardian [3].

(2) Research has shown that humans cannot help themselves. Cognitive psychologists such as [5] have shown that humans cannot effectively distinguish between fake news and real news. In fact, humans are only 4 percent better than chance (50\%) at doing so [6].

One key factor with fake news is that it can be persuasive. Persuasion implies efforts engaged to change people's attitudes through the use of various kinds of messages or information [7]. With particular reference to fake news, intentions could be to put persons in disrepute while upgrading or self-promoting the propagator of the news. However, it is worthy to note that not all persuasive messages are deceptive or are fake news.

Processing of persuasive information involves absorbing. interpreting and evaluating information. According to [7], persuasive messages are processed in two distinct ways. The first being the systematic processing or the central route, involves careful consideration of message content, the ideas it contains [7], the source of the information, and so on. As may be noticed, such processing is tasking and involves so much information processing capability. 
On the other hand, information may be processed heuristically using the peripheral route. This second approach engages the use of simple rules of thumb or mental shortcuts - such as the beliefs that professionals do not lie and that their information can be trusted or because the idea makes one feel good, it has to be true. Some theories on persuasion such as the Elaboration Likelihood Model simply labeled ELM stipulates that people engage in the effortful type of processing (systematic processing) when their capacity to process information relating to the message is high; when knowledge on the subject matter is vast, there is enough time for probing, when there is a motivation to do so, or when it is considered important to form accurate view $[8,9]$.

In contract, people indulge in the less effortful type of processing (heuristic processing) when they lack the ability or capacity to process more carefully and have to make up their minds very quickly. It could also be that they have little knowledge on the subject matter and motivation (drive) to perform such cognitive task is low as the issue is seen as unimportant or has little potential effect on them. Drivers of fake news are more likely to push readers into the heuristic mode of processing [7]. These express the need for a support system that could enable humans to determine which news is deceptive or real to aid our decision making.

(3) In order to help humans in distinguishing between real and fake news, machine-based approaches have been used. Numerous tools and methods have been developed to tackle this problem; browser extensions, deep learning, natural language processing, and so on. The solutions are often divided into Uniform Resource Locator (URL)-based and Corpora-based solutions. However, research has also shown the inadequacy of these machine-based approaches to effectively detect the fake news. [3] added that the use of URL-based solution has its drawbacks because there is no definitive list of fake news websites and one might disagree with the inclusion or exclusion of particular sites in the list. Just like the URL-based solutions, the corpora-based solutions have their limitations as they depend on a pre-existing knowledge-base.

An important question arises, since traditional fact checking and automated machine approach have limitations and cannot single-handedly solve the problem, we are proposing a hybrid approach that uses both the human and machine approaches to detect deceptive news on social media.

\section{HISTORY OF FAKE NEWS}

Fake news have evolved over a long time following interaction and communication among humans. They may be subtle such as infused exaggerations during conversations or even propaganda during wars or crises.

Literature considers the $18^{\text {th }}$ century as the official birth date of fake news [10]. Benjamin Franklin sent an entire fake letter in 1779 purportedly Capt. Samuel Gerrish. It was printed in such a way as to look like a regular newspaper supplement to a Boston newspaper writing about the cruelties that were committed by the British and their allies. He was explicitly looking to influence public opinion as the peace negotiations got under way. This point marked the birth of fake news. However, it would not have been possible to the degree we have today without another point in history, when the world wide web became publicly available. In 1991, the world wide web became publicly available when Tim Berners-Lee launched the first web page [11] and in 1997 the birth of social media websites [12]. Social media websites allowed increased communication speed and improved share ability but, with this blessing came its curse. Because of the trillions of contents generated by users per second, traditional news verification processes could not be used to police user-generated contents [2]. This gave room to an exponential rise of fake news.

\section{DEFINITION OF FAKE NEWS}

Fake news are news articles that are intentionally and verifiably false and could mislead readers [3]. This includes intentionally fabricated news and articles that originated from satirical websites. There are three broad types of fake news: serious fabrications, largescale hoaxes and humorous fakes [13].

Serious Fabrications: Fraudulent reporting are actually not unheard of [13]. Most fabrications are developed or devised to achieve self-branding or self-promotion of the reporter over public information authenticity, eye catching or deceptive headlines to lure viewers into clicking, exaggeration of reports to entice readers or for the purpose of fraudulent purposes, such as blackmail, defame and install hale.

Large-scale Hoaxes: These are deliberate fabrications detailed beyond simple pranks or practical jokes to something more complex to make it look like an authentic news in an attempt to deceive or mislead viewers. Viewers turned victims could incur material loss or could be harmed both physically or mentally [14]

Humorous Fakes: These are fabrications usually presented in the format of professional journalism [13] sometimes mimicking real news but also with intense parody that gives the audience a hint to alert them on the humorous nature or intent of the news. A form of 
this type of fake is News Satire - which is a news formatted professionally with content to imitate and make fun of or ridicule an original news. Some Humorous fakes sources are The Onion, The Daily Bonnet [15].

\section{IMPACTS OF DECEPTIVE NEWS}

There are a wide range of impacts of deceptive news in recent time. [16] in the post "Can fake news affect the stock market?" shows that deceptive news can have a major impact on the stock market, noting that in 2013, 130 billion USD in stock value was wiped out in minutes following an AP tweet about an "explosion" that injured Barack Obama. [14] points to the Chibok tragedy to explain the deadly danger of fake news. The terrorist organization Boko Haram kidnapped more than 200 schoolgirls from the town of Chibok, Nigeria. [14] said that around the world, the crime became epitomized by the slogan \#Bring Back Our Girls but in Nigeria, government officials called the crime a hoax, confusing and delaying any efforts to rescue the girls. Other examples are the impact fake news played in the American Presidential election. Although research said that fake news did not influence the outcome of the American President elections, 20\% of electorates said that news on social media influence their choice of candidate [15]. More examples are the hoax news on the death of the Nigerian President, Muhammadu Buhari [16].

\section{HUMAN AND MACHINE DECISION MAKING LIMITATION IN DETERMINING FAKE NEWS}

One would think humans with their intellectual capability will be able to distinguish between true and false news. But, it is not so. The findings of deception judgments meta-review conducted by [6] showed that humans can only distinguish between fake and real news $54 \%$ of the time (only $4 \%$ greater than chance) and machine can slightly outperform humans in restricted task [5].

Also, 59 percent of people only read the headlines of news articles before interacting with it; sharing it and having a view [17]

This does not get better for human decision making. According to cognitive psychologists, [18], a phenomenon called the "Illusory-truth effect" indicates that humans rated repeated statements as more true than new statements. On face value, this means when an information is repeated, it has more likelihood to be considered as true compared to an information that is true but has only been seen or heard once [19]. We can infer that a continuously repeated seen or heard fake news have more believability than a truthful news shown or heard once. This has been seen in a number of political campaigns where electoral candidates repeat a fake news over and over to slander the campaign of an opposing candidate knowing that as the public becomes more familiar with the information, they may come to believe it. The Illusory-truth effect also gives room to source monitoring errors meaning that not only will humans believe repeated news as true but will also believe it is from a genuine and reliable source. This is unintentional because when [19] experiment subjects were warned that the sources in their study may not be credible, it still did not seem to influence them.

In other cases, [20] also shows that humans often lack literacy skills required to inspect news items critically to make decisions if they are true or false. [21] also added that even when human decision was wrong, they will believe it to be true as long as they have evidence. This is not only scientific, the lack of our ability to discern deception is woven into our very cores. Quoting $[22]$, "...the main problems with deception is that we are not aware we are deceived."

All these findings have increased the need for more automated and data-centric ways to solving decision making challenges [2].

Machines cannot be exempted from this. In a wellknown artificial intelligence story documented beautifully by [23] titled the parable of the tank detector;

"Once upon a time, or so the story goes, the American military were developing a computer system that they could train to identify tanks on the battlefield. The approach involved connecting a 'neural network' to a camera. The training was to be done using photographs. So, the design team went out into the field and took 100 photographs of scenes with tanks in various orientations - out in the open, hiding behind trees, and the like. They also took 100 photographs of scenes with no tanks present. The system would be taught using both positive and negative cases.

They split all the photographs into two sets, one for training and one for testing the system after training had taken place. Using the training set, they showed the system pictures of tanks and said, "Tank". They also showed the system pictures without tanks and said, "No tank". Each time the system would first have a guess, and if shown to be wrong would adjust itself. A keen understanding would emerge, it was hoped, of the key features it needed to consider in making the right judgment. From entirely random beginnings the system's performance improved. It got so proficient that it could give a correct answer most of the time. The next step was to test the system on the remaining 
photos - the set that it had not yet seen. It behaved extremely well - perfectly in fact, categorizing every photo as either 'tank' or 'no tank' correctly. The designers decided to commission a further set of photos for more testing. The pictures came back and they were shown to the system. Only this time its performance was abysmal - no better than flipping a coin.

It took the designers a while to work out what was going on. It turned out that the original photographs with tanks and without tanks had been taken on different days. The 'tank' days happened to be sunny. The 'no tank' days had been cloudy. Each time the system was shown a photograph with a tank, it saw bright sunlight, blue skies and shadows. Each time it saw a photograph without a tank, it saw grey skies and an absence of shadows. This was the meaning of 'tank' it inferred. The designers had developed a sunny day detector, and a good one at that."

This story shows that (1) machines are also "not perfect" and (2) when Artificial Intelligence systems are trained using ostensive definition, we cannot say what exactly the system is actually learning.

\section{FAKE NEWS DETECTION SYSTEMS}

Fake news detection is a daunting but imperative task [2]. It is described as the task of predicting the likelihood that a particular news item is deceptive [13]. A fake news detection system is a support system designed to assist humans in the detection and filtering of potentially deceptive news [2]. By this description, it intends to support, assist or augment not to particularly make the decision by itself. A support system that support unaided human intuition, just as the goal of using a calculator is to aid human's limited capacity for mental arithmetic [27].

The methods to fake news detection are often divided into human-based and machine-based solutions (URLbased and corpora-based solutions). URL-based solutions are done by comparing the news item source with a database of truthful sources and the Corporabased compares the news item with a corpus of truthful news articles [13].

\subsection{Machine-based approach}

Conroy, et al [2] discussed two major approaches to detecting falsehood in online news; using linguistic cue approach with machine learning and network analysis approach. They went further to state need of a hybrid approach that combines the major machine related approaches with the aim of utilizing the two most effective deception detection methods.
The linguistic approach is corpora-based. In the linguistic approach, the content of deceptive messages is extracted and analyzed to associate language patterns with deception. In the network approach, the network information such as metadata or structured knowledge queries can be scrapped to provide aggregate deception measures. Both approaches normally incorporate machine learning techniques for training classifiers to suit the analysis.

\subsection{Linguistic Approach}

This approach relies on language usage and its analysis to predict deception. Peddlers of false information tend to use their language of conveyance in a strategic manner to avoid being caught or flagged with high likelihood of being false. According to [2], despite the attempts the peddlers put into language control. Language leakages occur but are quite difficult to monitor. The leakages could be frequencies in patterns of pronoun, conjunction, and even word usage that are influenced by negative feelings or emotions. Some measures put in place to identify and flag these "leakages" are; data representation (bag of words approach), deep syntax, semantic analysis, rhetorical structure and discourse analysis and training of classifiers [2].

\subsection{Network Approach}

The network approach was engineered to complement the content-based approaches such as the linguistic approach. This method relies on the perusal of existing body of collective human knowledge to assess the likelihood of new statements to be false [2]. The method goes beyond the analysis of the questionable content itself to collect and compare a wide range of similar and related statement from various sources (network) such as metatags and social network behaviour to ascertain the likelihood of the content being false.

Many commercial solutions have been developed using these approaches like browser extensions and native applications. For example;

(1) Official Media Bias and Fact Check Extension are corpora-based and use a comprehensive bias library to report bias.

(2) B.S. Detector is URL-based. It searches all links on a given webpage for references to unreliable sources. It then provides a visual warning about the presence of questionable links or the browsing of questionable websites. 
(3) FiB analysis is both URL-based, corpus-based and picture-based. It provides an algorithm that provides the user with a trust score. If the algorithm finds that the post is fake, it makes an attempt to find the truth and show the user.

(4) PolitiFace is a native application that provides a "Truth-0-Meter" to measure how true a news item is.

\subsection{Human-based approach}

Due to the limitation of machine-based solutions and the impossibility to manually verify every social media news post, many major new media companies like Google, Facebook, Twitter etc. have proposed the use of a more human approach to deceptive news detection, using news literacy education to aid people in spotting fake news. This is also in line with [14] thinking that humans should have a part to play on the detection of fake news. The most popular social media news literacy education tool available is that provided by Facebook called "Tips to Spot False News" [24]. It contains 10 (ten) measures to consider in order to determine if a news item is false. The measures include; heading, URL, news source, news formatting, photograph, date of publication, evidences, similar news sources, jokes and shareability.

\subsection{Hybrid Approach}

With the limitation of the human-based and machinebased decision-making approaches, there is a need for a novel approach [13]. One that combines the abilities of both humans and machines because neither humans or machines can be left to detect fake news on their own [25].

\section{THE HYBRID MODEL: MACHINE-HUMAN BASED SYSTEM}

In order to solve the issue of fake news detection, various solutions have been proposed and they can be loosely divided into machine-based and human-based solutions. Notwithstanding the solutions, research has drawn us to the limitations of both approaches from human literacy and cognitive limitations to machine learning limitations. It is common knowledge that the benefits of a hybrid model supersede the benefits and functions of its individual components. Because of this rationale, we are proposing a hybrid model of both the human-based and machine-based approaches. To do this, we combine the human-based social media news literacy education tool and the machine-based approaches for linguistic and network analyses.

\subsection{Description of hybrid model}

The function of the hybrid model (Machine-Human (MH) system) is to determine the likelihood that a news item is fake. So, not particularly say a news item is fake but that it has likelihood of being fake.

The social media news literacy education tool presents 10 factors to be considered while determining the likelihood of a news item to be fake. In Table 1 the explanation of the various factors is broken down into various checks and these checks are further broken down into the current approach and the proposed approach that will be used to check for the factor i.e. some factors can be checked by a machine approach, while others a human approach and others a combination of both a machine and human approach. Human parts are parts that a human is essentially needed and machine-part in contrary are parts that a machine is needed and human-machine parts requires both human and machine involvement.

Table 1: 10 factors to spot false news with their individual descriptions broken into checks and approach for performing the checks.

\begin{tabular}{lllll}
\hline Factors & Tip & Explanation broken down into checks & $\begin{array}{l}\text { Current } \\
\text { Approach }\end{array}$ & $\begin{array}{c}\text { Proposed } \\
\text { Approach }\end{array}$ \\
\hline A & $\begin{array}{l}\text { Be skeptical of } \\
\text { headlines }\end{array}$ & $\begin{array}{l}\text { 1.1Does it have all caps? } \\
\text { 1.2Does it have excessive exclamation } \\
\text { points? } \\
\text { 1.3Do other users rate the headline as } \\
\text { unbelievable }\end{array}$ & Human & $\begin{array}{l}\text { Human } \\
\text { /Machine }\end{array}$ \\
B & Look closely at & $\begin{array}{l}\text { 2.1 Does the URL belong to the deceptive } \\
\text { news database }\end{array}$ & Human & Machine \\
the URL & Investigate the & 3.1 Is the source a reputable source? & Human & Machine \\
\hline
\end{tabular}




\begin{tabular}{|c|c|c|c|c|}
\hline Factors & Tip & Explanation broken down into checks & $\begin{array}{l}\text { Current } \\
\text { Approach }\end{array}$ & $\begin{array}{l}\text { Proposed } \\
\text { Approach }\end{array}$ \\
\hline $\mathrm{D}$ & $\begin{array}{l}\text { Watch for } \\
\text { unusual } \\
\text { formatting }\end{array}$ & $\begin{array}{l}\text { 4.1 Are the formatting the same? } \\
\text { 4.2 Are there spelling mistakes? }\end{array}$ & Human & Machine \\
\hline $\mathrm{E}$ & $\begin{array}{l}\text { Consider the } \\
\text { photos }\end{array}$ & $\begin{array}{l}5.1 \text { Do people rate the image as } \\
\text { manipulative? }\end{array}$ & Human & Human \\
\hline $\mathrm{F}$ & Inspect the date & 6.1 Does it have an old date? & Human & Machine \\
\hline G & $\begin{array}{l}\text { Check the } \\
\text { evidence }\end{array}$ & $\begin{array}{l}\text { 7.1 Are there any references } \\
\text { 7.2 If they are, are they in the reliable list }\end{array}$ & Human & Machine \\
\hline $\mathrm{H}$ & $\begin{array}{l}\text { Look at other } \\
\text { reports }\end{array}$ & $\begin{array}{l}\text { 8.1 Are there any similar news } \\
\text { 8.2 Did reliable source report similar news }\end{array}$ & Human & Machine \\
\hline I & $\begin{array}{l}\text { Is the story a } \\
\text { joke }\end{array}$ & $\begin{array}{l}9.1 \text { is it categorized as a joke? } \\
9.2 \text { is the source known to provide jokes }\end{array}$ & Human & $\begin{array}{l}\text { Human / } \\
\text { Machine }\end{array}$ \\
\hline $\mathrm{J}$ & $\begin{array}{l}\text { Some stories are } \\
\text { intentionally } \\
\text { false }\end{array}$ & 10.1 Was it rated as false by other users? & Human & Human \\
\hline
\end{tabular}

A to J are respective nodes with a parent node of $\mathrm{MH}$. The sum of the 10 factors labelled $A$ to $\mathrm{J}$ is equal or less than 100.

$\mathrm{MH}=\sum(\mathrm{A}, \mathrm{B} \ldots \mathrm{J})$

Where $\mathrm{MH} \leq 100$

Each node has one or more connected children nodes From table 1, some factors have more than one subfactor for example the factor A has 3 sub-factors.

The sum of an individual node is equal or less than 10 . For example, node $\mathrm{A} \leq 10$.

Below is a syntax tree visualizing the factors and their sub factors. The syntax trees are constructed using graphical syntax trees generator software designed by [26] called phpSyntaxTree. The syntax tree reflects a more visual underlying rule (production rule) set of the user's representation [27].

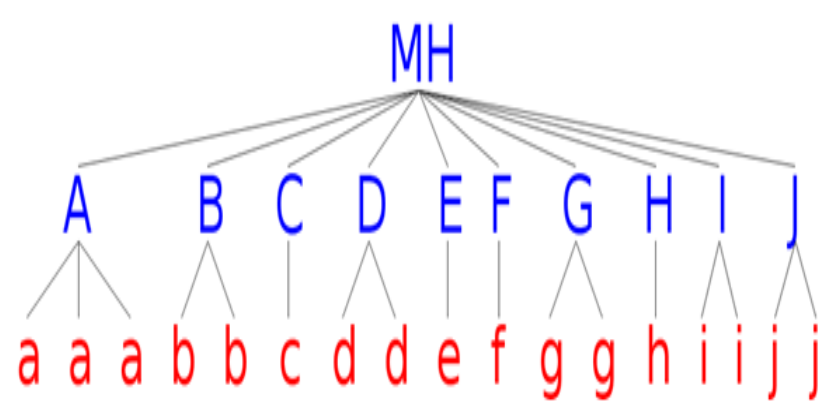

Figure 1: showing a syntax tree visualizing the underlining of the Machine-Human model

i. Analysis of model individual nodes
The $A=\left\{a_{1}+a_{n}\right\}$

where $\mathbf{n}$ are the numbers of respective conditions for node $\mathbf{A}$ factor check or the numbers of sub-factors in a factor

$\mathrm{A}=\sum\left[\mathrm{a}_{1 \mathrm{i}}+\mathrm{a}_{\mathrm{ni}}\right] \leq 10$

Where the individual sub-factors

$\left[\mathrm{a}_{1 \mathrm{i}}+\mathrm{a}_{\mathrm{ni}}\right] \leq 10 / \mathrm{n}$

Where $\mathrm{i}=1$, the value of $\mathrm{i}=10 / \mathrm{n}$, otherwise $\mathrm{i}=0$

$\therefore \mathrm{MH}=\Sigma[\mathrm{A}+\mathrm{B} \ldots \mathrm{J} \leq 100]$

Using node A (Headlines check) as case study, node A checks through three conditions as part of the headlines criteria to check for the likelihood that the news item is false.

$\mathrm{a}_{1}$ Does it have all caps letters?

$\mathrm{a}_{2}$ Does it have excessive exclamation points?

$\mathrm{a}_{3}$ Does other users rate it as unbelievable?

Each of these 3 conditions sums up to be equal or less than 10 . Where individual condition has a value of $10 / n$ where $n=3$

$A=\left\{a_{1}, a_{2}, a_{3}\right\}$ where $a 1, a 2, a 3$ are respective conditions for headlines check

$\mathrm{A}=\sum\left[\mathrm{a}_{1 \mathrm{i}}+\mathrm{a}_{2 \mathrm{i}}+\mathrm{a}_{3 \mathrm{i}}\right] \leq 10$

Where each node with value $i=1$ is equal to $10 / 3$ and value $i=0$ is equal to 0

Where $i=1$, the value of $i=10 / 3$, otherwise $i=0$

The sum results of each nodes [A.... J] is equal or less than 100.

$\mathrm{MH}=\left(\left(\mathrm{a}_{1}+\mathrm{a}_{2}+\mathrm{a}_{3}\right)+\left(\mathrm{b}_{1}\right)+\left(\mathrm{c}_{1}\right)+\left(\mathrm{d}_{1}+\mathrm{d}_{2}\right)+\left(\mathrm{e}_{1}\right)+\left(\mathrm{f}_{1}\right)+\right.$ $\left.\left(\mathrm{g}_{1}+\mathrm{g}_{2}\right)+\left(\mathrm{h}_{1}+\mathrm{h}_{2}\right)+\left(\mathrm{i}_{1}+\mathrm{i}_{2}\right)+\left(\mathrm{j}_{1}\right)\right)$

Where $\mathrm{MH}=\sum[\mathrm{A}+\mathrm{B}+\mathrm{C}+\mathrm{D} \ldots+\mathrm{J}] \leq 100$ 


\subsection{Programmable model}

Figure 2 shows the factors and their associated conditions, linking conditions that require human intervention (user input) and those that depend on a standardized false news database.

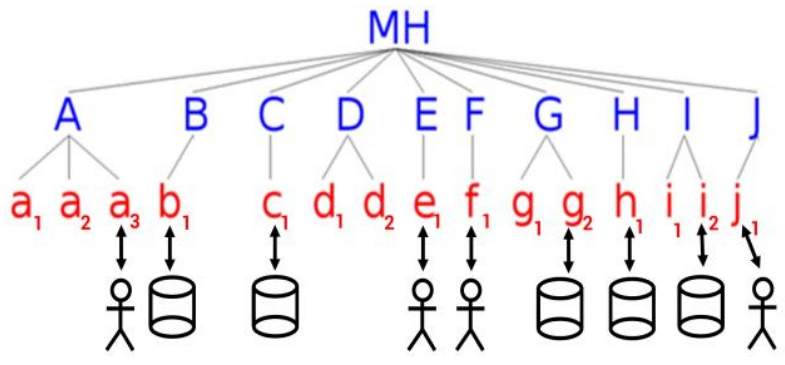

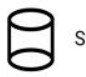

Standardized false news database

으 User Input

Figure 2: showing a syntax diagram visualizing the underlining of the Machine-Human model with its components.

Below is a programmable representation of the model $\mathrm{MH}\{$

A \{

A1 does a basic machine-check to see if the heading (title of the news) in all in Uppercase

A2 does a basic machine-check to see if the heading (title of the news) has excessive exclamation marks (!)

A3 User is asked "Do you rate the heading as false? Yes or No"

A3 results $=$ the collective median user rating (including this particular users responses) of all answers

\}

B \{

B1 does a database check in the standardized false news database to see if URL belongs to the deceptive news database

C \{$$
\}
$$

C1 does a database check in the Standardized false database)

// the standardized database distinguish news URL into reliable and non-reliable sources

$\mathrm{D}\{$ \}

D1 does a basic machine check to check if the article formatting is the same
D2 does a basic machine check to check if there are spelling mistakes

\}

E \{

E1 User is asked "Do you rate the image as manipulative?" Yes or No

E1 results $=$ the collective median user rating (including this particular users responses) of all answers

\}

$\mathrm{F}\{$

F1 User is asked, "Does the news item look recent?" Yes or No

F1 result $=$ the collective median user rating (including this particular users responses) of all answers

\}

G \{

G1 - does a basic machine check to check if any source is in document

G2 - If a source is available in article, check with the standardized database for reliability

\}

$\mathrm{H}\{$

H1 - check with standardized database similar news

$\mathrm{H} 2$ - If there are similar news, machine using a network-based approach compares this news with news presented by reliable sources \}

I \{

I1 - machine using the linguistic approach, determines if the content contains jokes.

I2 - Check with standardized database if the news source is known for jokes

$\mathrm{J}\{$

\}

J1 - User is asked, "is this news false to you?" Yes or No

$\mathrm{J} 1$ Result $=$ the collective median user rating (including this particular users responses) of all answers.

\}

\}

The sum results of each nodes [A.... J] is equal or less than 100.

$\mathrm{MH}=\left(\left(\mathrm{a}_{1}+\mathrm{a}_{2}+\mathrm{a}_{3}\right)+\left(\mathrm{b}_{1}\right)+\left(\mathrm{c}_{1}\right)+\left(\mathrm{d}_{1}+\mathrm{d}_{2}\right)+\left(\mathrm{e}_{1}\right)+\left(\mathrm{f}_{1}\right)+\right.$ $\left.\left(\mathrm{g}_{1}+\mathrm{g}_{2}\right)+\left(\mathrm{h}_{1}+\mathrm{h}_{2}\right)+\left(\mathrm{i}_{1}+\mathrm{i}_{2}\right)+\left(\mathrm{j}_{1}\right)\right)$

Where $\mathrm{MH}=\sum[\mathrm{A}+\mathrm{B}+\mathrm{C}+\mathrm{D} \ldots+\mathrm{J}] \leq 100$

\subsection{Model Limitations}

The following are the limitations of the $\mathrm{MH}$ model descried in early sections;

Vol. 37, No. 2, April 2018 
1. Literature does not point to any standardized fake news database that (a) stores all social media news, (b) distinguish news into reliable source and non-reliable source, (c) distinguish URL based on (i) known for jokes and (ii) known for real news

2. The model allows users to be promoted to provide their feedback and there is currently no database with user inputs on news.

3. The model would need an extended library of native African names because one of the nodes analyses spelling errors and these names may be counted as spelling errors.

\section{CONCLUSIONS}

The detection of fake news is a highly relevant problem because of human literacy and cognitive limitations and the inadequacy of machine-based approach, there is a need for a hybrid model solution that combines the efforts of both humans and machine. Based on these, this paper has proposed a Machine-Human (MH) model to fake news detection in social media. The model combines the human literacy news detection tool and the machine linguistic and network-based approaches. We argued that when the hybrid approach is employed in fake news detection, it means that two "parallel approaches" of detection are at work, each helping to provide a balance for the other. If we are right that there is a benefit in the combined approach of man and machine, then the benefits should be quantifiable or empirical. But what are the measures to be considered? At one hand, this is a classification task. Hence, given a dataset of real and fake social media news, a study can be conducted to test if the model supports and improve the human ability to distinguish fake news with a higher accuracy than when they are left on their own. Here, we ask participants to perform a small news classification test in which they will review news articles and organize them as fake and real using the model and without the use of the model. Based on literature, we are hypothesizing that users using the model will perform better at distinguishing between fake and true news than users not using the tool. We intend to report the results of this study as future work. It is important that we can adequately distinguish fake from real news because of the immense impacts it has shown in the past. Also with the Nigerian Presidential elections coming in 2019, who knows what electorates will do with fake news.

\section{REFERENCES}

[1] J. Gottfried and E. Shearer, "News Use Across Social Media Platforms 2016," 26 May 2016. [Online]. Available: http://www.journalism.org/ 2016/05/26/news-use-across-social-mediaplatforms-2016/.

[2] N. J. Conroy, V. L. Rubin and Y. Chen, "Automatic Deception Detection: Methods for Finding Fake News," in ASIS\&T Annual Meeting: Information Science with Impact: Research in and for the Community, St. Louis, MO, USA., 2015.

[3] H. Allcott and M. Gentzkow, "Social Media and Fake News in the 2016 Election," Journal of Economic Perspectives, pp. 211-236, 2017.

[4] G. L. Ciampaglia, P. Shiralkar, L. M. Rocha, J. Bollen, F. Menczer and A. Flammini, "Correction: Computational Fact Checking from Knowledge Networks," PLoS ONE, vol. 10, no. 6, 2015.

[5] V. Rubin and N. J. Conroy, "Discerning truth from deception: Human judgments \& automation efforts," First Monday, March 2012.

[6] C. J. Bond and B. M. DePaulo, "Accuracy of deception judgments.," Personality and Social Psychology Review, vol. 10, no. 3, pp. 214-234, 2006.

[7] R. A. Baron and D. Bryne, Social Psychology, London: Allyn and Bacon, 2000.

[8] D. Maheswaran and S. Chalken, "Promoting Systematic Processing in Low Motivation Settings: Effect of Incongruent Information on Processing and Judgment," Journal of Personality and Social Psychology, pp. 1762 - 1776, 1991.

[9] R. E. Petty and J. T. Cacioppo, "Involvement and Persuasion; Tradiction Versus Integration," Psychological Bulletin, pp. 367 - 374, 1990.

[10] D. Russell, "Benjamin Franklin / the problem of 18th century fake news / ladybugs," 1 March 2017. [Online]. Available: http://fia.umd.edu/benjamin-franklin-theproblem-of-18th-century-fake-newsladybugs/2017.

[11] L. Candler, "Hunt For The First Web Page Leads To UNC-Chapel Hill," 12 June 2013. [Online]. Available: http://wunc.org/post/hunt-first-webpage-leads-unc-chapel-hill, 2013,

[12] B. Hale, "The History of Social Media: Social Networking Evolution!," 2016. [Online]. Available: http://historycooperative.org/the-history-ofsocial-media/,2016.

[13] V. L. Rubin, N. J. Conroy, Y. Chen and S. Cornwell, "Fake News or Truth? Using Satirical Cues to Detect Potentially Misleading News," in Association for Computational Linguistics: Human 
Language Technologies, San Diego, California, 2016.

[14] J. H. Brunvand, American Folklore: An Encyclopedia, Taylor \& Francis, 1998.

[15] Wikipedia, "News Satire," 2017. [Online]. Available: en.wikipedia.org/wiki/ News_ satire. [Accessed 06 July 2017].

[16] K. Rapoza, "Forbes," 2017. [Online]. Available: https://www.forbes.com/sites/kenrapoza/2017/ $02 / 26 /$ can-fake-news-impact-the-stockmarket/\#5e66ab9d2fac. [Accessed 06 July 2017].

[17] S. Busari, "How fake news does real harm," 24 April 2017. [Online]. Available: https://ted.com/talks/stephanie busari how fak e news does real harm/., 2017

[18] M. Anderson, "Social media causes some users to rethink their views on an issue," 7 November $2016 . \quad$ [Online]. Available: http://www.pewresearch.org/facttank/2016/11/07/social-media-causes-someusers-to-rethink-their-views-on-an-issue/2016.

[19] O. J. Nwachukwu, "Ex-British lawmaker,Eric Stuart pronounces President Buhari dead," 22 May 2017. [Online]. Available: http://dailypost.ng/2017/05/22/ex

British_lawmaker_eric_stuart_pronounces_preside nt_buhari_dead.

[20] M. Gabielkov, A. Ramachandran, A. Chaintreau and A. Legout, "Social Clicks: What and Who Gets Read on Twitter?," Proceedings of the 2016 ACM SIGMETRICS International Conference on Measurement and Modeling of Computer Science, pp. 179-192, 2016.

[21] L. Hasher, D. Goldstein and T. Toppino, "Frequency and the conference of referential validity," Journal of Verbal Learning, pp. 107-112, 1977.

[22] D. C. Polage, "Making up History: False Memories of Fake News Stories," Europe's Journal of Psychology, vol. 8, no. 2, pp. 245-250, 2012.

[23] D. W. Hango, "University graduates with lower levels of literacy and numeracy skills," Statistics Canada: Insights on Canadian Society, 2014.

[24] E. M. Okoro, "A study of different representation conventions during investigatory sensemaking," Middlesex University Research Repository, London, 2014.

[25] S. Thompson, You may all prophesy, United States of America.: The Apple Orchard Publishing, 2010.

[26] L. Chapin, S. Attfield and E. M. Okoro, "Predictive Coding, Storytelling and God: Narrative Understanding in e-Discovery," in DESI V Workshop, Consiglio Nazionale delle Ricerche, Rome, Italy, 2013.

[27] M. J. Druzdzel and R. R. Flynn, "Decision Support Systems," Encyclopedia of Library and Information Science, 2002.

[28] Facebook, "Tips to Spot False News," 2017. [Online]. Available: https://web.facebook.com/help/1881188083573 79?_rdc=1\&_rdr.

[29] B. B. Scott, Using Collective Thinking to Develop an Effective Approach toDecision Making, Kingston, Ontario: Queen's University IRC, 2014.

[30] M. Eisenbach and A. Eisenbach, 2003. [Online]. Available: http://ironcreek.net/phpsyntaxtree/.

[31] C. Zander, "Language grammar," 2009. [Online]. Available: http://courses.washington.edu/css448/zander/N otes/langGrammar.pdf. 